\title{
EFEITO DA CONCENTRAÇÃO DE CULTURAS PROBIÓTICAS NA FERMENTAÇÃO DE UMA BEBIDA DE SOJA
}

\author{
Diego R.S.F. Paim ${ }^{1}$, Selma C. Terzi ${ }^{2}$, João P. B. Torres ${ }^{3}$, Simone D. Oliveira², Ana P.O. \\ Ribeiro², Vanessa F. Mello², Erika F. Souza', Edmar M. Penha², Leda M.F. \\ Gottschalk ${ }^{2}$, Eduardo H.M. Walter ${ }^{2}$
}

\footnotetext{
${ }^{1}$ Universidade Estadual da Zona Oeste. Av. Manuel Caldeira de Alvarenga 1203, 23070-200, Rio de Janeiro.

${ }^{2}$ Embrapa Agroindústria de Alimentos. Av. das Américas 29501, 23.020-470, Rio de Janeiro, Brasil.

${ }^{3}$ Colégio de Aplicação Emmanuel Leontsinis (CAEL)

E-mail para contato: leda.fortes@embrapa.br
}

\section{RESUMO}

As culturas probióticas são um insumo fundamental na elaboração de bebidas probióticas. As culturas precisam apresentar desempenho de processo compatível com o custo do produto, além de contribuir para o equilíbrio da microbiota intestinal, dentre outras propriedades funcionais. $O$ objetivo deste trabalho foi estudar o efeito da concentração de culturas comerciais de Bifidobacterium animalis subsp. lactis e Lactobacillus acidophilus na fermentação de bebidas de soja. Foram realizadas fermentações da bebida de soja com diferentes concentrações de culturas liofilizadas (0,1\%; 0,01\%; 0,001\%) até valores de pH final de 5,3; 5,0 e 4,7. Nas concentrações de culturas liofilizadas estudadas e pH final de fermentação selecionados foi possível obter bebidas de soja probióticas em conformidade com os requisitos legais. Esses parâmetros podem influenciar consideravelmente o tempo de fermentação e o custo de produção da bebida, assim como a concentração final de probióticos.

\section{INTRODUÇÃO}

Os alimentos probióticos são aqueles que contêm micro-organismos vivos que, se administrados em quantidades adequadas, auxiliam nas funções digestivas, imunológica e respiratória, podendo ter um efeito significativo sobre o alívio de doenças infecciosas em crianças e outros grupos de alto risco (FAO/WHO 2006). Estes tem que estar em concentrações adequadas para que um produto seja considerado probiótico. O desafio tecnológico no desenvolvimento de alimentos com probióticos é estabelecer uma rota de processo para alcançar e manter a viabilidade dos microrganismos em concentrações necessariamente elevadas, desde a produção do alimento até o momento do consumo (CHAMPAGNE; GARDNER; ROY, 2005; FARI; WALTER; CRUZ, 2011). 


\section{SIMPÓSIO NACIONAL DE BIOPROCESSOS \\ XI SIMPÓSIO DE HIDRÓLISE ENZIMÁTICA DE BIOMASSA}

01 a 04 de setembro de 2015

Fortaleza, Ceará, Brasil

A fermentação é um processo de transformação reconhecido por alterar as características sensoriais e o valor nutricional dos alimentos, bem como suas propriedades funcionais. Considerando que a soja é uma fonte proteica de alta qualidade e de baixo custo, mas de menor aceitação devido ao seu sabor, os derivados fermentados probióticos representam uma oportunidade de diferenciação e agregação de valor a produtos derivados da soja.

O enfoque principal deste trabalho foi estabelecer o efeito da concentração de culturas liofilizadas comerciais na fermentação de bebidas de soja, etapa fundamental no desenho de processos industriais. Foram estudadas culturas das principais cepas de probióticos empregadas em produtos alimentícios: Bifidobacterium animalis subsp. lactis e Lactobacillus acidophilus.

\section{MATERIAL E MÉTODOS}

\subsection{Preparação do inóculo}

\section{Culturas}

As culturas empregadas nos experimentos foram de Bifidobacterium animalis subsp. lactis BB-12 (Chr. Hansen, SP - Brasil) e Lactobacillus acidophilus (Granotec, PR - Brasil). As culturas liofilizadas foram fornecidas em sacos laminados e mantidas em congelador a $-20^{\circ} \mathrm{C}$ até o momento de uso.

\section{Inóculo}

O inóculo de cada cultura foi preparado a partir da dissolução de 2,6 g da cultura liofilizada em 100 $\mathrm{ml}$ de solução aquosa de soja. Essas soluções foram preparadas com extrato de soja em pó (Marca Provesol SM-N Olvebra Industrial, RS - Brasil), na concentração de $6 \%(\mathrm{~m} / \mathrm{v})$; submetidas à pasteurização lenta em temperatura na faixa de 70 a $75^{\circ} \mathrm{C}$ por 2 minutos, seguindo-se o resfriamento até $40^{\circ} \mathrm{C}$. A preparação do inóculo foi finalizada pela manutenção das amostras em caixas de isopor por 15 minutos, de modo a hidratar e condicionar as culturas liofilizadas.

\subsection{Fermentação}

As bebidas de soja foram formuladas com $8 \%(\mathrm{~m} / \mathrm{v})$ de açúcar, $6 \%(\mathrm{~m} / \mathrm{v})$ de extrato de soja em pó e água potável. As mesmas foram aquecidas sob agitação e submetidas à pasteurização lenta até atingir a faixa de temperatura de 70 a $75^{\circ} \mathrm{C}$ por 2 minutos, seguida de resfriamento em banho de água a temperatura ambiente até atingirem a faixa de temperatura de 45 a $40^{\circ} \mathrm{C}$.

A inoculação foi realizada em concentrações iniciais de 0,001\%; 0,01\% e 0,1\% (m/v). A fermentação foi conduzida em banho termostático a $42^{\circ} \mathrm{C}$ até a bebida atingir os valores de $\mathrm{pH}$ na ordem de 5,3 ; 5,0 e 4,7. $\mathrm{O}$ pH foi monitorado em intervalos de 20 minutos. 


\section{SIMPÓSIO NACIONAL DE BIOPROCESSOS \\ XI SIMPÓSIO DE HIDRÓLISE ENZIMÁTICA DE BIOMASSA}

01 a 04 de setembro de 2015

Fortaleza, Ceará, Brasil

Ao término da fermentação as bebidas foram transferidas para garrafas de polietilenoterftalato com tampa de rosca de polipropileno e imersas em banho de gelo até temperatura inferior a $10^{\circ} \mathrm{C}$. A estocagem foi efetuada em câmara fria a $8 \pm 2^{\circ} \mathrm{C}$.

\subsection{Análise Microbiológica}

A determinação de micro-organismos probióticos foi realizada a partir da diluição seriada de uma amostra da bebida de soja fermentada em água peptonada $0,1 \%(\mathrm{~m} / \mathrm{v})$. Para as amostras de $L$. acidophilus a contagem de unidades formadoras de colônia (UFC) foi realizada em placas de Petri por inoculação em profundidade com adição de sobrecamada em meio MRS (De Man, Rogosa \& Sharpe, 1960), incubadas a $35^{\circ} \mathrm{C}$ por 72 horas. Para as amostras contendo B. animalis subsp. lactis, as placas foram incubadas em jarras de anaerobiose contendo sistema de remoção de oxigênio (INTERLAB, SP, Brasil).

\subsection{Análise Estatística}

A análise estatística dos dados coletados foi realizada por Análise de Variância (ANOVA) e as diferenças significantes entre as médias $(p<0.05)$ foram avaliadas pelo teste de Bonferroni, utilizando o software Prism v. 5.03 (GraphPad Software, Inc., 2010).

\section{RESULTADOS}

3.1. Crescimento Lactobacillus acidophilus e Bifidobacterium animalis subsp. Lactis na bebida de soja

A contagem de células viáveis foi realizada para as diferentes concentrações iniciais de inóculo e de $\mathrm{pH}$ final de fermentação. Os resultados das contagens de células viáveis de $L$. acidophilus estão descritos na Tabela 1.

Tabela 1. Contagem de células viáveis de L. acidophilus para diferentes concentrações iniciais de inóculo e pH final de fermentação.

\begin{tabular}{|c|c|c|c|c|c|}
\hline \multirow{3}{*}{$\begin{array}{l}\text { Código } \\
\text { da } \\
\text { amostra }\end{array}$} & \multirow{3}{*}{$\begin{array}{l}\text { Concentração } \\
\text { de inóculo } \\
(\% \mathrm{~m} / \mathrm{v})\end{array}$} & \multirow[t]{2}{*}{ pH inicial } & \multicolumn{3}{|c|}{ pH final da fermentação } \\
\hline & & & 5,3 & 5,0 & 4,7 \\
\hline & & \multicolumn{4}{|c|}{ Contagem de células viáveis (log UFC/ml) } \\
\hline A & 0,001 & $6,98 \pm 0,05$ & $7,93 \pm 0,49^{a, x}$ & $7,90 \pm 0,53^{a, x}$ & $7,93 \pm 0,45^{a, x}$ \\
\hline B & 0,01 & $7,02 \pm 0,08$ & $7,31 \pm 0,08^{a, y}$ & $7,10 \pm 0,14^{a, y}$ & $6,73 \pm 0,19^{b, y}$ \\
\hline C & 0,1 & $8,04 \pm 0,03$ & $8,21 \pm 0,10^{a, x}$ & $8,21 \pm 0,09^{a, x}$ & $8,16 \pm 0,08^{a, x}$ \\
\hline
\end{tabular}

Resultados expressos em Média \pm Desvio-Padrão de duas repetições.

Letras diferentes na mesma linha e na mesma coluna indicam que existe diferença estatisticamente significante entre as médias ( $p<0,05)$, pelo teste de Bonferroni.

Na fermentação por L. acidophilus foi possível observar que as concentrações finais de células viáveis em A e C estavam na mesma ordem de grandeza, independente do pH final. Além disso, a 


\section{SIMPÓSIO NACIONAL DE BIOPROCESSOS \\ XI SIMPÓSIO DE HIDRÓLISE ENZIMÁTICA DE BIOMASSA}

01 a 04 de setembro de 2015

Fortaleza, Ceará, Brasil

diferença entre as médias obtidas para cada concentração de inóculo não foi estatisticamente significante $(p<0.05)$. Em comparação com essas concentrações, a concentração B de inóculo apresentou médias de contagem de células inferiores em todos os valores de $\mathrm{pH}$ final de fermentação.

Os resultados da contagem de células viáveis de $B$. animalis subsp. lactis estão descritos na Tabela 2. Em função de dificuldades na condução do processo fermentativo, a contagem de células viáveis para a concentração $\mathbf{D}$, no $\mathrm{pH} \mathrm{4,7}$ foi inviabilizada. Dessa forma, não foi realizada a análise de variância e testes de comparação de médias.

Tabela 2. Contagem de células viáveis de B. animalis subsp. lactis para diferentes concentrações de inóculo e pH final de fermentação da fermentação.

\begin{tabular}{cccccc}
$\begin{array}{c}\text { Código } \\
\text { da } \\
\text { amostra }\end{array}$ & $\begin{array}{c}\text { Concentração } \\
\text { de inóculo } \\
(\mathbf{\%} \mathrm{m} / \mathrm{v})\end{array}$ & pH inicial & \multicolumn{3}{c|}{ pH final da fermentação } \\
D & $\mathbf{0 , 0 0 1}$ & $\mathbf{7 , 3 3 \pm 0 , 0 5}$ & $\mathbf{5 , 3}$ & $\mathbf{5 , 0}$ & $\mathbf{4 , 7}$ \\
E & $\mathbf{0 , 0 1}$ & $7,83 \pm 0,12$ & $8,20 \pm 0,08$ & $8,12 \pm 0,13$ & $6,86 \pm 0,06$ \\
F & $\mathbf{0 , 1}$ & $9,00 \pm 0,19$ & $8,93 \pm 0,01$ & $8,99 \pm 0,23$ & $9,18 \pm 0,17$ \\
\hline
\end{tabular}

Resultados expressos em Média \pm Desvio-Padrão.

Ao se comparar as concentrações de inóculo de $\mathbf{D}$ e $\mathbf{E}$ com a concentração de $\mathbf{F}$, é possível observar que, assim como L. acidophilus, as médias de contagem de células de B.animalis subsp. lactis foram inferiores em todos os valores de $\mathrm{pH}$ final de fermentação.

O aumento da contagem de células na concentração de $\mathbf{D}$ de inóculo sugere que utilizar uma menor quantidade de inóculo permite que as células se adaptem melhor ao meio. Esse resultado é de interesse industrial, pois possibilita a utilização de uma menor quantidade de inóculo para se obter a mesma contagem final de bactérias probióticas.

Considerando-se uma porção de referência de $200 \mathrm{ml}$ para essa bebida de soja desenvolvida, todos os experimentos garantiriam a concentração de probióticos requerida pela legislação brasileira (8 $9 \log$ UFC/porção de referência), independente do pH e concentração inicial de inóculo.

\subsection{Cinética de acidificação}

$\mathrm{O}$ pH inicial da bebida de soja em todos os experimentos foi em torno de 6,5. A variação de pH da fermentação da bebida de soja foi monitorada desde a inoculação até o pH atingir o valor de 5,3; 5,0 e 4,7, indicativo do fim da fermentação. A evolução do pH ao longo do processo de fermentação da bebida probiótica de soja para $L$. acidophilus e $B$. animalis subsp. lactis é apresentada nas figuras 1 e 2 , respectivamente.

Embora as contagens de células viáveis nos inóculos de $B$. animalis subsp. lactis tenham sido maiores que as de L. acidophilus, o declínio do $\mathrm{pH}$ foi mais rápido para as culturas de $L$. acidophilus. $\mathrm{Na}$ maior concentração de inóculo $(0,1 \%)$, o tempo necessário para atingir o $\mathrm{pH} 4,7$ foi de aproximadamente $2,5 \mathrm{~h}$, enquanto para $B$. animalis subsp. lactis, o tempo foi de aproximadamente 


\section{SIMPÓSIO NACIONAL DE BIOPROCESSOS \\ XI SIMPÓSIO DE HIDRÓLISE ENZIMÁTICA DE BIOMASSA}

01 a 04 de setembro de 2015

Fortaleza, Ceará, Brasil

3,5 h. A utilização de menores quantidades de inóculo aumentou substancialmente o tempo do processo para ambas as culturas.

Para B. animalis subsp. lactis, a concentração de $0,01 \%$ de inóculo apresentou tempo de fermentação similar que a concentração de 0,001\%.

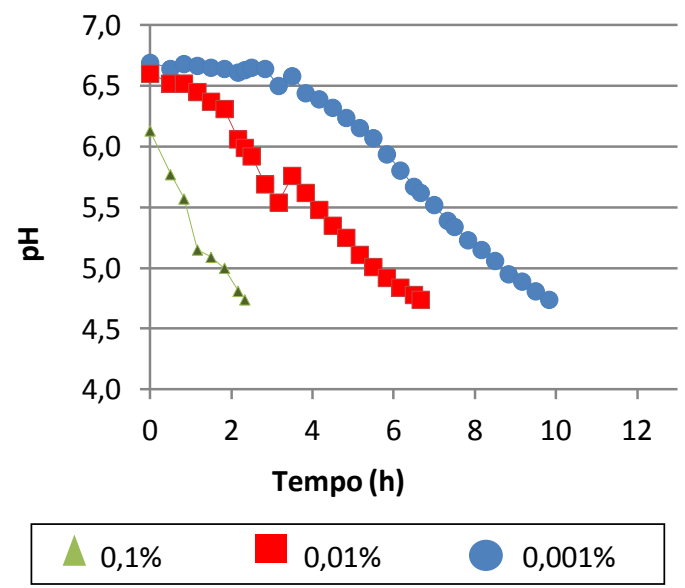

Figura 1. Evolução do $\mathrm{pH}$ ao longo do processo de fermentação da bebida probiótica de soja por $L$. acidophilus em diferentes concentrações de inóculo.

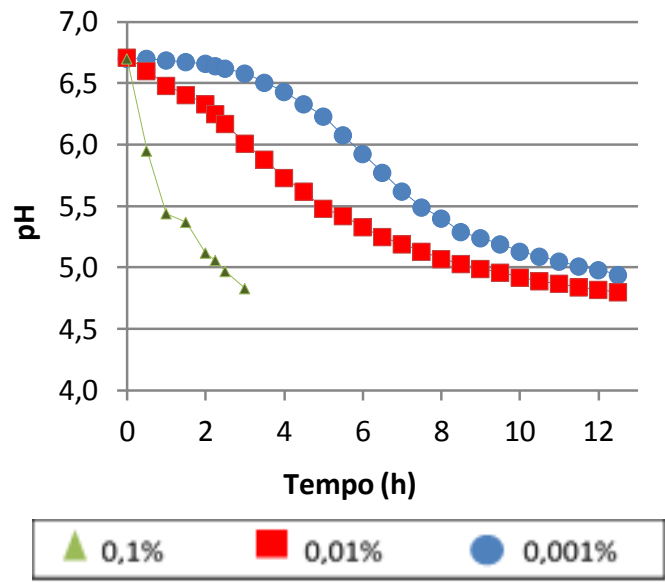

Figura 2. Evolução do $\mathrm{pH}$ ao longo do processo de fermentação da bebida probiótica de soja por $B$. animalis subsp. lactis em diferentes concentrações de inóculo.

\section{CONCLUSÃO}

Nas concentrações de culturas liofilizadas estudadas e pH final de fermentação selecionados foi possível obter bebidas de soja probióticas de acordo com os requisitos legais relativos à concentração de células viáveis. Esses parâmetros de fermentação e o tipo de bactéria empregada podem influenciar consideravelmente o tempo de fermentação e o custo de produção da bebida, assim como a concentração de probióticos. A seleção desses parâmetros depende de fatores como sistema de produção empregado, produtividade e características desejadas para o produto final. Estudos futuros serão conduzidos de modo a determinar o efeito do $\mathrm{pH}$ da bebida na viabilidade dos probióticos durante a estocagem.

\section{REFERÊNCIAS}

Champagne, C.P., Gardner, N.J. and Roy, D. Challenges in the addition of probiotic cultures to foods. Critical Reviews in Food Science and Nutrition, v.45, p. 61-84, 2005.

De Man J. C., Rogosa M. and Sharpe M. E. A medium for the cultivation of lactobacilli. Journal of Applied Bacteriology, $\quad$ v. 23, p.130-135, 1960.

[FAO; WHO] Food and Agriculture Organization of The United Nations; World Health Organization. Probiotics in food - Health and nutritional properties and guidelines for evaluation. Rome: 


\title{
XX SIMPÓSIO NACIONAL DE BIOPROCESSOS \\ XI SIMPÓSIO DE HIDRÓLISE ENZIMÁTICA DE BIOMASSA
}

\author{
01 a 04 de setembro de 2015 \\ Fortaleza, Ceará, Brasil
}

FAO/WHO, 2006. 50p. (FAO Food and Nutrition Paper 85)

Faria, J.A.F., Walter, E.H.M., Cruz, A.G. Sistemas de embalagem para alimentos prebióticos e probióticos. In: Probióticos e prebióticos em alimentos: Fundamentos e aplicações tecnológicas. São Paulo: Varela, 2011. p. 163-194. 